\title{
HOSPITAL DISCHARGES IN RELATION TO AREA OF RESIDENCE
}

\author{
ROSAMOND GRUER, M.B., Ch.B., Dip.Soc.Med. \\ Department of Social Medicine, University of Edinburgh
}

AREA of residence is an item of considerable importance to be recorded with other data concerning patients using medical services. Numerous uses for this information come readily to mind.

In the national planning of hospital services, area of residence of patients is required for the mapping of catchment areas of individual hospitals and groups of hospitals, and for the demonstration of the direction of flow of patients towards medical services from different areas. Such information may also be of value in helping to select the boundaries of areas which would be the most appropriate for the regions to be administered by Area Health Boards.

Comparisons of morbidity in different geographical areas and variations in the use of hospital and other medical services also require an accurate record of patients' residences.

\section{Area of Residence in In-PATIENT Statistics}

The Scottish Home and Health Department prepare annually computer-processed statistical tables compiled from data collected at hospital level for each patient on discharge. Area of residence is one of the items so recorded and the patient's address is used to allocate a five-digit numerical code for this purpose. In the case of patients from cities and large burghs, this number refers to the city or burgh, and municipal ward in which the patient's home is situated. In the case of rural patients, it refers to the county and rural civil parish of residence.

Defects in this system of recording the area of residence were brought to light recently in the course of a study of the use of hospital in-patient services by patients living in four rural counties of Scotland. Striking results were obtained when the possible effect of distance from a general practitioner on the probability of a patient being admitted to hospital was investigated. Civil parishes in the counties which were studied were divided into two categories -those in which a general practitioner's surgery is situated and those in which there is none. It was found that, on average, the rate of discharge from hospital of persons from the former category of parishes was six times greater than that of persons from the latter. Before continuing more detailed work on this subject, it was decided to check the accuracy of coding addresses in the survey counties, although it seemed most unlikely that such a large difference could be produced by coding mistakes.

\section{Factors Affecting Coding}

The method adopted was first to consider the factors which could affect the accuracy of recording the area of residence and then to check the coding of an appropriate sample of addresses of patients discharged from hospital.

City wards and civil parishes are artificial areas designated by outlines on maps and are used for administrative purposes. The only strictly accurate method of allocating a residence to one of these areas would be by map reference. An address, on the other hand, is a vital link in the chain of communication and, when given by a patient on admission to hospital, it is for this purpose that it is given. Although this obviously has some relation to the geography of the area, it is related more to the direction of roads and the position of G.P.O. sorting offices and routes which could conveniently be taken by postmen delivering letters, and not to outlines on maps. An address may use place names that are familiar in the area, but these may not coincide with the actual geographical location of the residences. It is essential, therefore, to consider how accurately the use of addresses in rural areas allocates patients to the correct civil parish.

Rural civil parishes in Scotland can be divided into three categories according to the postal address:

1. Rural Parish which is a Main Postal Address. The parish has the same name as a main centre for the distribution of mail situated within its boundaries. The system of mail distribution is such that addresses in other neighbouring parishes will contain this name, and, unless coding clerks are aware of this, addresses in these parishes will be wrongly coded to the parish containing the postal centre.

2. Rural Parish which Contains a Main Postal 
ADDRESS. This type of parish contains a main centre for the distribution of mail, but the parish and the centre have different names. Coding clerks are likely to make efforts to find out the name of the parish in which this centre lies, as many addresses will contain the name of that centre. Addresses of residences in the surrounding parishes will also contain the name of this centre and may be wrongly coded.

3. Rural Parishes which are not Main Postal ADDRESSES. This type of parish contains no centre for the distribution of mail and all correct postal addresses of residences in these parishes will contain the name of a centre in another parish. Unless coding clerks are aware of this, such addresses may be wrongly coded to parishes in one of the other categories.

In coding a sample of 399 rural addresses, it was found that 60 to $70 \%$ could be coded correctly if, in addition to the instructions issued to the hospitals, The Census Book of Place Names in Scotland, a gazetteer, parish outline maps and a one-inch ordnance survey map were also used. This was very tedious and time-consuming. A much higher proportion could be coded with less effort, using county valuation rolls. Unfortunately, these varied greatly in format and in the ease with which the required information could be obtained.

Other factors which influence the accuracy of recording addresses are the training and experience of the hospital staff carrying out the coding. Large hospitals employ records clerks, but in small rural hospitals coding is carried out by typists or matrons, who, however, would have a smaller area in which patients' addresses are likely to be located. Accuracy may also be affected by the attitude of the staff-the importance they attach to this aspect of their work, their awareness of the difficulties involved in coding addresses, and the efforts they make to provide themselves with additional aids for coding difficult addresses.

\section{Method Used to Check Accuracy of Coding}

Samples of addresses of patients discharged from two hospitals in 1966 were taken. Hospital A drew a high proportion of its patients from the counties in which there were apparent marked differences in rates of discharge. The other, Hospital B, admitted patients from a city and surrounding rural areas. The addresses were coded by the author of the survey, using the same numerical coding system. The areas of residence were identified by consulting oneinch ordnance survey maps, county valuation rolls and postal directories. These codes were assumed to be correct and were compared with the code numbers which had been allocated to the same addresses for the statistical returns.
Hospital A. It was found that all parishes in the counties served by Hospital A fell into categories 1 and 3-those that were main postal addresses and those that were not. Two systematic samples of addresses of discharged patients were taken from Hospital A. Sample I was a sample of all addresses, so that the overall rate of error could be calculated. Sample II was designed to include a high proportion of addresses in parishes which were not main postal addresses together with a proportion of those which were main postal addresses but might be difficult to code.

Analysis of Survey at Hospital A. Sample I contained 202 addresses. The country was incorrectly coded in $3(1.5 \%)$, the county in $16(7.9 \%)$, and the rural parish in $49(28.4 \%)$.

TABLE I

HOSPITAL A: SAMPLE I

\begin{tabular}{l|c|c}
\hline & $\begin{array}{c}\text { Parishes which are } \\
\text { Main Postal } \\
\text { Addresses } \\
\text { (No. of addresses) }\end{array}$ & $\begin{array}{c}\text { Parishes which are } \\
\text { not Main Postal } \\
\text { Addresses } \\
\text { (No. of addresses) }\end{array}$ \\
\hline $\begin{array}{c}\text { Incorrectly coded to } \\
\text { parish in same category } \\
\text { parish in other category }\end{array}$ & $16(10.3 \%)$ & $1(2.6 \%)$ \\
\hline $\begin{array}{l}\text { Total incorrectly coded } \\
\text { Correctly coded }\end{array}$ & $\begin{array}{c}16(0) \\
140(89.7 \%)\end{array}$ & $\begin{array}{c}33(84.6 \%) \\
6(5.4 \%)\end{array}$ \\
\hline Total in sample & $156(100 \%)$ & $39(100 \%)$ \\
\hline
\end{tabular}

TABLE II

HOSPITAL A: SAMPLE II

\begin{tabular}{l|c|c}
\hline & $\begin{array}{c}\text { Parishes which are } \\
\text { Main Postal } \\
\text { Addresses } \\
\text { No. of addresses) }\end{array}$ & $\begin{array}{c}\text { Parishes which are } \\
\text { not Main Postal } \\
\text { Addresses } \\
\text { (No. of addresses) }\end{array}$ \\
\hline $\begin{array}{c}\text { Incorrectly coded to } \\
\text { parish in same category } \\
\begin{array}{c}\text { Incorrectly coded to } \\
\text { parish in other category }\end{array}\end{array}$ & $20(23.8 \%)$ & $2(1.8 \%)$ \\
\hline $\begin{array}{l}\text { Total incorrectly coded } \\
\text { Correctly coded }\end{array}$ & $20(0)$ & $103(92.0 \%)$ \\
\hline Total in sample & $85(100 \%)$ & $105(93.8 \%)$ \\
\hline
\end{tabular}

Table I shows the size and direction of error in the two categories of parish in sample I.

Table II shows the distribution of error between the different categories of parish in sample II.

In neither sample were any addresses in the 'main postal address' category mis-allocated to the 'not main postal address' category. On the other hand, in sample I, $82 \%$ and, in sample II, $92 \%$ of addresses in the 'not main postal address' category were wrongly allocated to the 'main postal address' category. 
A continuum of increasing degree of error can be traced as addresses become more difficult to code, as is illustrated in Table III.

TABLE III

HOSPITAL A: SAMPLES I AND II

\begin{tabular}{l|c|c}
\hline & $\begin{array}{c}\text { No. of Addresses } \\
\text { Incorrectly Coded }\end{array}$ & $\begin{array}{c}\text { Total No. of } \\
\text { Addresses Coded }\end{array}$ \\
\cline { 2 - 3 } & $3(1.5 \%)$ & $202(100 \%))^{1}$ \\
\hline $\begin{array}{c}\text { Country } \\
\text { County } \\
\text { All parishes which are } \\
\text { main postal addresses }\end{array}$ & $16(10.3 \%)$ & $156(100 \%)$ \\
$\begin{array}{c}\text { Parishes which are main } \\
\text { postal addresses and } \\
\text { are difficult to code }\end{array}$ & $20(23.8 \%)$ & $85(100 \%)^{2}$ \\
$\begin{array}{c}\text { Parishes which are not } \\
\text { main postal addresses }\end{array}$ & $105(93.8 \%)$ & $112(100 \%)$ \\
\hline
\end{tabular}

'Data from sample I

'Data from sample II

Effect of Error. The main effect of these mistakes is to give rise to false assumptions about apparent differences in discharge rates between those parishes which are main postal addresses and those which are not.

The original study had found marked differences in rates of discharge from hospital between parishes in which a general practitioner's surgery is situated and those in which there is none; it was now seen that, with one exception, all of the former were parishes which were main postal addresses, and all of the latter were not. The magnitude and direction of error in allocating addresses was more than enough to account for these differences. This is a salutary reminder that in epidemiological studies, however strong circumstantial evidence may be, association between apparently relevant factors may not necessarily be that of cause and effect.

Hospital B. A systematic sample of all addresses of discharged patients was taken from Hospital B. This included city and rural addresses.

Analysis of Survey of Hospital B. The sample contained 129 rural addresses. The country was incorrectly coded in $1(0.8 \%)$, the county in $6(4.8 \%)$, and the rural parish in $35(27 \cdot 1 \%)$.

From a total of 206 city addresses, $42(19.3 \%)$ were found to have been allocated to the wrong municipal ward. Further analysis of this misallocation of city addresses showed that postal addresses, although responsible for a small proportion of errors, did not have the same effect on coding city addresses as on coding rural addresses.

In the city the error was greatest in the municipal wards with the smallest total number of addresses, suggesting that the error is greater in the areas with which the coding clerks are least familiar. This is shown in Table IV.
TABLE IV

HOSPITAL B

\begin{tabular}{|c|c|c|c|}
\hline $\begin{array}{l}\text { Total No. of } \\
\text { Addresses in } \\
\text { Each Ward }\end{array}$ & $\begin{array}{l}\text { Total No. of } \\
\text { Addresses in } \\
\text { Each Category }\end{array}$ & $\begin{array}{c}\text { No. of } \\
\text { Addresses } \\
\text { Undercoded }\end{array}$ & $\begin{array}{l}\text { No. of } \\
\text { Addresses } \\
\text { Overcoded }\end{array}$ \\
\hline $\begin{array}{r}>30 \\
20-30 \\
10-20 \\
<10\end{array}$ & $\begin{array}{l}41 \\
27 \\
41 \\
97\end{array}$ & $\begin{array}{r}3(7.3 \%) \\
4(14.8 \%) \\
11(26.3 \%) \\
24(24.7 \%)\end{array}$ & $\begin{array}{c}6(14.6 \%) \\
7(7.4 \%) \\
10(24.4 \%) \\
24(24.7 \%)\end{array}$ \\
\hline Total & 206 & $42(19.3 \%)$ & $42(19.3 \%)$ \\
\hline
\end{tabular}

Looking at individual wards, it was found that, in general, overcoding balanced out undercoding. This balancing-out effect is such that total rates of discharge for municipal wards could be used with confidence. Although this is a small study of only one hospital in its own catchment area, it should be borne in mind that similar errors are likely to occur in other hospitals. If catchment areas of individual hospitals were being defined, it should be remembered that, at the outer limits, error is likely to be larger, causing a 'blurring of the outline'.

It must be pointed out, however, that all these errors in coding city addresses could be avoided by the use of the Postal Directory which gives the municipal ward of each street or part of a street.

It is interesting to note that no significant differro ence was found between the two hospitals in the overall error of recording rural addresses.

\section{ERrors Throughout Scotland}

It was considered to be important to discover whether similar errors in coding addresses in rural areas existed throughout Scotland. Some indication of this could be obtained by comparing crude discharge rates for individual parishes and aggregates of parishes in each of the three categories defined at the beginning of this paper.

This was done, using 1966 Scottish In-Patient Discharge Statistics and 1961 Census Population data.

Figure 1 shows the distribution of discharge rates of aggregates of parishes at regional level in each category.

In each hospital region, and in Scotland as a whole, the discharge rates of aggregates of parishes which are not main postal addresses are considerably lower than the overall regional rate and the rates in the other two categories. Differences of the same order were found when comparisons were made between the discharge rates of aggregates of parishes at county level. It seems reasonable to assume that these differences are due to mis-classification by wrong code allocation.

Supportive evidence was obtained by examining 


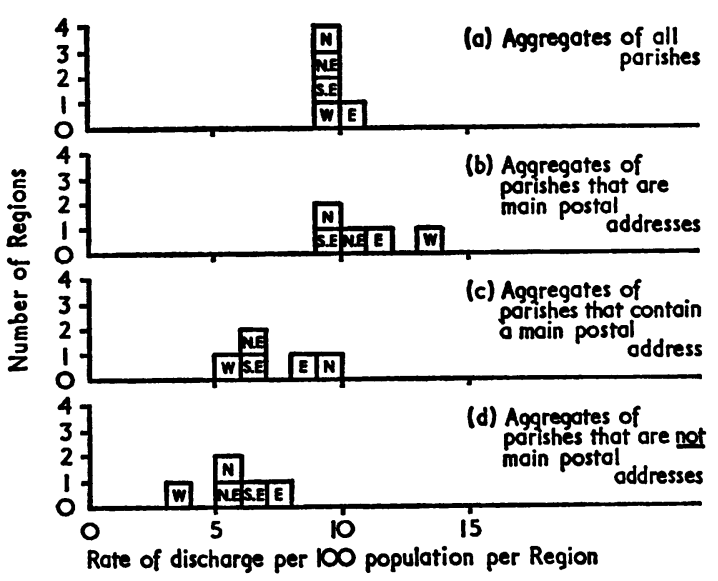

Fig. 1. Distribution of discharge rates in Regional Hospital Board areas.

the discharge rates of individual parishes in each category. In all regions, the mean rate of discharge in parishes which are main postal addresses was significantly higher than the mean rate of discharge in parishes which are not main postal addresses, in the Northern Region at the $5 \%$ level, and in all other regions at the $1 \%$ level.

\section{'DRAINAGE' EFFECT}

Additional supportive evidence was obtained by indicating on a parish outline map of Scotland the category and discharge rate of each parish. It was found, without exception, that a parish with a high rate was adjacent to one or more parishes with very low rates. Although, in the majority of cases, 'drainage' appeared to be from 'not main postal address' parishes to 'main postal address' parishes, it also occurred, in a small number of cases, in either direction between any two categories of postal address. This is illustrated in Fig. 2, which shows part of the south-east of Scotland. This would seem to support the argument that difficulties arising from the system of postal addresses in Scotland have been responsible for errors in coding the area of residence of patients discharged from hospitals in all regions. In addition, there is evidence to suggest that the occurrence in each region of other types of errors in allocating addresses is likely to be due to local factors which could only be uncovered by investigations at hospital level.

\section{Discussion}

Although the discovery of such errors in coding addresses is disquieting, it is only fair to point out that rural parish errors affect only one-eighth of the

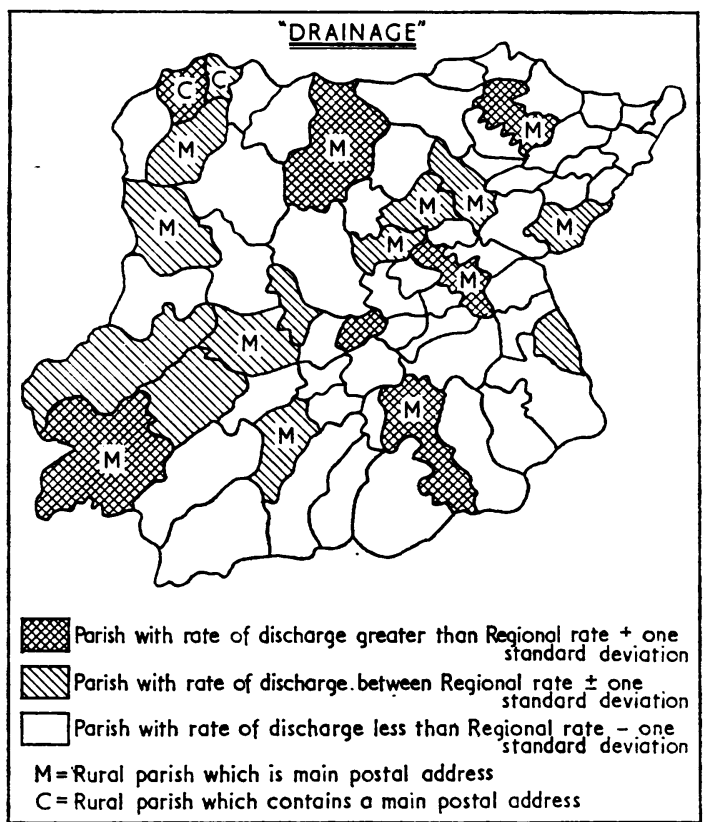

FIG. 2. Outline map of part of south-east Scotland showing category and discharge rate of each parish.

whole population. The error at county level is within acceptable limits, and discharge data at this level could be used with confidence.

Similar difficulties have been experienced elsewhere. A study in the United States in 1960 (U.S. Department of Health, Education and Welfare, 1969) revealed that postal addresses were responsible for mis-allocation of the place of residence on death certificates.

In Scotland, considerable efforts have been made to overcome difficulties in coding addresses for the vital statistical tables of the Registrar General. The primary units of area of residence-districts of county-are larger than civil parishes and the possibility of error, therefore, is considerably reduced. Over many years, comprehensive lists of places and appropriate codes have been compiled and the coding is central.

In England and Wales, an area code, designed primarily for use within the General Register Office, is used in different branches of vital and health statistics. This standard code has also been recommended for hospitals and cancer registries which may be required to submit records to the General Register Office for processing. This is a four-digit numerical code, the smallest identifiable areas being rural and urban districts. In the explanatory notes, no warning is given of difficulties which may arise 
from the system of postal addresses. It is possible, therefore, that coding errors, similar to those found in rural districts of Scotland, may be occurring at rural and urban district level in England and Wales. This should be borne in mind when interpreting the results of epidemiological studies in such areas and when outlining hospital catchment areas.

\section{Proposed Remedy}

Although the discovery of an error of this kind in national statistics is disturbing, it would be irresponsible to suggest that this discredits the whole system. It does not affect published tables, since civil parish data are available only on request. Although it is important to know the existence of this error, its magnitude, cause, and the limitations it imposes at the present time, the next logical step is to devise an alternative system.

If the area of residence is to be recorded routinely for large numbers of individuals, it is essential that this should be done accurately and should not involve a large number of staff in tedious, timeconsuming, and, therefore, costly work.

Several proposals were considered, but the system which seems most likely to meet with required criteria is the new Postal Code.

The General Post Office has planned that, by 1972, all addresses in Great Britain will have codes to facilitate the mechanical sorting of mail, and it is intended that these codes should be permanent. It is proposed to divide the country into 150 postal areas. Codes have already been allocated to 48 areas, of which three are in Scotland. Directories will be published giving a complete list of all addresses and the appropriate code for each.

The postal code consists of four letters and two, three or four numerals indicating different geographical areas. The smallest identifiable unit is a postman's round, which will not exceed 60 addresses. These are combined to form sections, which in turn are combined into postal districts. Finally, postal districts are combined into areas, which may comprise a city and several counties. Part of the code for each address is assigned to each sub-division. Although the boundaries of the postal areas do not coincide with the boundaries of any existing admini-

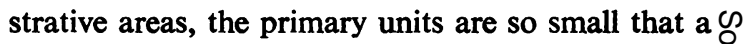
computer could be programmed to reassemble these units into any suitable aggregates.

There are other advantages. The recording of $\stackrel{\mathbb{Q}}{?}$ addresses would be simple, since no decision would $\Rightarrow$ be required of the recorder. If the patient did not $\stackrel{\text { s) }}{+}$ know his code, it would be obtainable from the directory of addresses and appropriate codes. $\frac{\bar{F}}{\bar{n}}$ Samples of addresses for surveys would be readily $\overrightarrow{\mathbb{D}}_{\vec{D}}$ available and easily identifiable.

If the Registrar General also decided to use this system, which would greatly facilitate the collection $\overrightarrow{0}$ of census and vital statistics data, population, vital statistics and hospital data would be available $\vec{\omega}$ for the same geographical areas, which could be, $\frac{\Omega}{\text {. }}$ but need not necessarily be, those which have been used traditionally.

\section{SUMMARY}

A study of hospital discharge rates in a rural $\vec{N}$ area of Scotland disclosed very large differences? between parishes with a general practitioner's surgery and those without. The accuracy of coding 3 the area of residence was suspected and a detailed study of coding is reported.

The present system of postal addresses in rurif areas in Scotland is shown to be a major factor the mis-allocation of addresses in certain ruril parishes. This was responsible for the differences found in the study of discharge rates.

The use of the new Postal Code for recording the area of residence is suggested as a possible solution to this problem.

I wish to acknowledge the helpful advice and criticism I have received in the preparation of this paper from Walter Lutz, Senior Lecturer in Statistics, Department of Social Medicine, University of Edinburgh.

This investigation was financed by a research fellow-? ship granted by the Scottish Home and Health Department.

\section{REFERENCE}

U.S. Department OF Health, Education AND Welfare (1969). Comparison of the Classification of Place of Residence on Death Certificates and Matching Census $D$ Records, United States, May-August 1960. National Center for Health Statistics, Series 2, no. 30, p. 4. N Washington. 